\title{
Perineural invasion is a better prognostic factor than extranodal extension in head and neck cancer
}

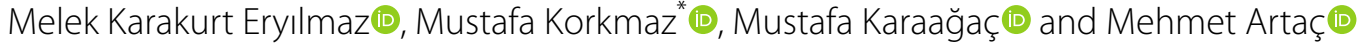

\begin{abstract}
Background: The prognostic value of perineural invasion (PNI) in head and neck squamous cell carcinoma (HNSCC) remains controversial. This study investigated the impact of PNI on prognosis in HNSCC. A total of 49 patients with HNSCC who underwent primary surgical treatment were selected for the study. Univariate analysis of the survival curve was performed using the Kaplan-Meier method. Multivariate analysis was carried out by Cox regression.

Results: PNI was present in 17 of 49 (34.7\%) patients. The median follow-up was 18.7 months. The median DFS and OS were 16.6 months and 41.9 months, respectively. Univariate analyses showed that PNI was associated with OS ( $p$ : 0.02 ), but not with DFS ( $p: 0.50)$. ENE was associated only with DFS in univariate analysis ( $p: 0.04)$, but not OS (yes vs. no; 24.1 vs. 44.6 months, $p: 0.21$ ), and in multivariate analysis, ENE lost its significance for DFS (p: 0.12). Also, PNI was the only significant independent adverse prognostic factor for OS in multivariate analysis ( $p$ : 0.02). The median OS for patients with and without PNI was 17.1 months and 92.1 months, respectively.

Conclusion: PNI was an independent factor for poor prognosis in patients with HNSCC. The presence of PNI compared to ENE was associated with a greater risk of death in HNSCC. Therefore, it would be appropriate to consider adjuvant therapy in the presence of PNI alone without other adverse risk features.
\end{abstract}

Keywords: Head and neck cancer, Perineural invasion, Extranodal extension, Prognosis

\section{Background}

Head and neck cancers (HNC) can occur in the oral cavity, pharynx, larynx, nasal cavity, paranasal sinuses, thyroid, and salivary glands and include various histopathological tumors. However, squamous cell carcinoma (SCC) is the most common histological type in these tumors. The stage at the time of diagnosis predicts survival rates and guides management in HNC patients. The 2017 version of the tumor, node, metastases (TNM) staging system of the American Joint Committee on Cancer (AJCC) and the Union for International Cancer Control (UICC) is used to stage HNC [1]. More advanced stages of TNM are associated with worse survival. Close or positive surgical margins and other adverse prognostic risk features such as perineural invasion (PNI), lymphovascular invasion (LVI), and extranodal extension (ENE) increase the risk of local recurrence $[2,3]$. Therefore, postoperative adjuvant therapy is recommended for patients with positive surgical margins, lymph node metastases (N2-3), or ENE to improve survival and loco-regional tumor control for HNC [4-6].

The prognostic significance of PNI seems to vary depending on different subtypes of HNSCC and tumor stages, so we aimed to evaluate the prognostic impact of PNI in patients with HNC.

\footnotetext{
*Correspondence: dr.musstafa@gmail.com

Department of Medical Oncology, Necmettin Erbakan University School of Medicine, Akyokuş, 42080 Konya, Turkey
} 


\section{Methods}

We retrospectively reviewed the medical records of HNC patients. Patients diagnosed with head and neck squamous cell carcinoma (HNSCC) who underwent surgical resection of the primary tumor with appropriate neck dissection at our hospital between January 1, 2009, and December 31, 2019, were included. This study was performed according to the Declaration of Helsinki and was approved by the Local Ethics Committee of Meram Faculty of Medicine, Necmettin Erbakan University, Turkey (Ethics Committee approval number: 2020/2750). Patients with nasopharyngeal cancer were not included. Also, HNSCC patients with metastatic disease at initial diagnosis, previously treated, and with recurrent disease were excluded from the study. In addition, patients who had inadequate information about PNI and ENE in their pathological reports, who did not continue their oncological followup, and whose records in their electronic or manual medical files could not be accessed were not included in the study. As a result, the data of 49 patients who met the inclusion criteria were analyzed.

The detailed clinicopathological data such as age, gender, adjuvant treatment methods, recurrence status at follow-up, tumor location, tumor diameter, tumor invasion depth, tumor cell differentiation, lymph node status, pathological ENE, borderline status, LVI, and PNI were recorded. The pathological $\mathrm{T}$ and $\mathrm{N}$ staging of the patients, which were previously performed according to the 7th edition of the AJCC staging system, was restaged according to the 8th edition of the AJCC staging system. The patients were divided into two groups as PNI+ and PNI- according to the presence or absence of PNI.

The patient's demographic and clinical features were compared according to PNI status using chi-square tests or Fisher's exact test for categorical variables and independent $t$-tests for continuous variables. Continuous variables were expressed as medians (ranges), and categorical variables were expressed as numbers and percentages. Survival rate estimates between PNI+ and PNI- groups were calculated by the KaplanMeier method and compared via a stratified log-rank test. Disease-free survival (DFS) was defined as the time from the surgery to the date of development of locoregional recurrence or distant metastasis. And, overall survival (OS) was defined as the time from the surgery to the date of death from any cause. Multiple logistic regression analyses were performed to determine the predictors on DFS and OS. The factors that revealed a statistical significance in univariate analyzes were controlled in multivariate analysis. Multivariate analyses were performed using the Cox proportional hazards regression model. A $p$-value of $<0.05$ was considered significant. We also calculated the $95 \%$ CI for the median time to event.

\section{Results}

The study included 49 patients, 39 men (79.6\%) and 10 women $(20.4 \%)$, with a median age of 57 years (range 36-82 years), and a median follow-up of 18.7 months. Tumors were most commonly found in supraglottic larynx $(n=11,22.4 \%)$, followed by the tongue $(n=11$, $22.4 \%)$, and subglottic larynx $(n=8,16.3 \%)$. The common tumor grade was grade 1 (49\%). PNI, LVI, and ENE were present in 17 (34.7\%), 16 (32.7\%), and 20 (40.8\%) patients, respectively. Positive resection margins were observed in 10 patients (20.4\%). Bilateral neck dissection was performed in 37 patients $(75.5 \%)$. Adjuvant RT was given to 39 (79.5\%) patients, with 33 of these also receiving concurrent chemotherapy. A summary of relevant demographic and clinicopathologic features is provided in Table 1.

Perineural invasion was significantly associated with LVI $(p=0.02)$, but not lymph node metastasis $(p=0.72)$. Apart from that, there was no difference between PNIand $\mathrm{PNI}+$ groups regarding median age, gender, $\mathrm{T}$ stage, ENE, grade, surgery margin, adjuvant treatment, and recurrence (Table 2).

At the last follow-up, 13 patients (26.5\%) were alive without disease, and 11 patients (22.4\%) were living with the disease (particularly with distant metastasis). During follow-up, recurrence at any site was found in 31 patients $(63.3 \%)$ : local recurrence in 8 patients $(16.3 \%)$, regional in 7 (14.3\%), and distant in 16 (32.7\%). Also, 25 patients (51\%) had died. The median DFS and OS were 16.6 months and 41.9 months, respectively (Figs. 1 and 2).

Univariate analyses of other clinicopathological factors and the presence of PNI were performed to explore the factors affecting the prognosis. Among the factors analyzed, pathological $\mathrm{N}$ stage (N0-1 vs. N2-3; 69.5 vs. 9 months; $p$ : 0.001 ), ENE (yes vs. no; 9.6 vs. 22.2 months, $p: 0.04$ ), and adjuvant treatment (yes vs. no; 22.2 vs. 8.2 months, $p$ : 0.003 ) were significant prognostic factors for DFS. The significant factors affecting OS were pathological $\mathrm{N}$ stage (N0-1 vs. N2-3; 92.1 vs. 32.5 months, $p$ : 0.04 ) and PNI (yes vs. no; 17.1 vs. 92.1 months, $p$ : 0.02 , Fig. 3 ). PNI (yes vs. no; 10.4 vs. 16.9 months, $p: 0.50$ ) was not a significant prognostic factor for DFS. Similarly, ENE (yes vs. no; 24.1 vs. 44.6 months, $p$ : 0.21 ) was not a significant prognostic factor for OS. Other factors such as age, sex, pathological $\mathrm{T}$ stage, and LVI did not significantly affect DFS and OS (Table 3). 
Table 1 Clinicopathological characteristics of all patients

\begin{tabular}{|c|c|}
\hline Variable & $n(\%)$ \\
\hline Median age, years (range) & $57(36-82)$ \\
\hline \multicolumn{2}{|l|}{ Sex } \\
\hline Men & 39 (79.6) \\
\hline Women & $10(20.4 \%)$ \\
\hline \multicolumn{2}{|l|}{ Grade } \\
\hline Well differentiated & $24(49)$ \\
\hline Moderately differentiated & $13(26.5)$ \\
\hline Poorly differentiated & $12(24.5)$ \\
\hline \multicolumn{2}{|l|}{ Site of tumor } \\
\hline Supraglottic larynx & $11(22.4)$ \\
\hline Glottic larynx & $5(10.2)$ \\
\hline Subglottic larynx & $8(16.3)$ \\
\hline Tonsil & $2(4.1)$ \\
\hline Oral cavity & $2(4.1)$ \\
\hline Lip & $4(8.2)$ \\
\hline Tongue & $11(22.4)$ \\
\hline Paranasal sinus & $2(4.1)$ \\
\hline Salivary gland & $3(6.1)$ \\
\hline Hypopharynx & $1(2)$ \\
\hline \multicolumn{2}{|l|}{ LVI } \\
\hline Yes & $16(32.7)$ \\
\hline No & $33(67.3)$ \\
\hline \multicolumn{2}{|l|}{ PNI } \\
\hline Yes & $17(34.7)$ \\
\hline No & $32(65.3)$ \\
\hline \multicolumn{2}{|l|}{ ENE } \\
\hline Yes & $20(40.8)$ \\
\hline No & $19(59.2)$ \\
\hline \multicolumn{2}{|l|}{ Margin status } \\
\hline Clear & 39 (79.6) \\
\hline Involved by tumor & $10(20.4)$ \\
\hline \multicolumn{2}{|l|}{ Pathological T classification } \\
\hline $\mathrm{T} 1$ & $2(4.1)$ \\
\hline $\mathrm{T} 2$ & $17(34.7)$ \\
\hline T3 & $17(34.7)$ \\
\hline $\mathrm{T} 4 \mathrm{a}$ & $13(26.5)$ \\
\hline \multicolumn{2}{|l|}{ Pathological N classification } \\
\hline No & $16(32.7)$ \\
\hline N1 & $6(12.2)$ \\
\hline $\mathrm{N} 2 \mathrm{~b}, \mathrm{~N} 2 \mathrm{c}$ & $3(6.1), 5(10.2)$ \\
\hline N3b & $19(38.8)$ \\
\hline \multicolumn{2}{|l|}{ Treatment } \\
\hline Surgery & $10(20.4)$ \\
\hline Surgery + radiotherapy & $6(12.2)$ \\
\hline Surgery + chemoradiotherapy & $33(67.3)$ \\
\hline
\end{tabular}

LVI lymphovascular invasion, $P N I$ perineural invasion, ENE extranodal extension
Table 2 Demographic and disease characteristics of patients according to PNI status

\begin{tabular}{|c|c|c|c|}
\hline & $\begin{array}{l}\text { PNI- } \\
\text { (n:32,\%) }\end{array}$ & $\begin{array}{l}\text { PNI+ } \\
(n: 17, \%)\end{array}$ & $p$ value \\
\hline \multicolumn{4}{|l|}{ Characteristics } \\
\hline \multicolumn{4}{|l|}{ Median age, years } \\
\hline$<57$ & $16(50)$ & $7(41.2)$ & 0.55 \\
\hline$\geq 57$ & $16(50)$ & $10(58.8)$ & \\
\hline Gender & & & 0.69 \\
\hline Male & $26(81.3)$ & $13(76.5)$ & \\
\hline Female & $6(18.8)$ & $4(23.5)$ & \\
\hline T stage & & & 0.11 \\
\hline $\mathrm{T} 1-2$ & $15(46.9)$ & $4(23.5)$ & \\
\hline T3-4 & $17(53.1)$ & $13(76.5)$ & \\
\hline \multicolumn{4}{|c|}{ Lymph node metastasis } \\
\hline Yes & $21(65.6)$ & $12(70.6)$ & 0.72 \\
\hline No & $11(34.4)$ & $5(29.4)$ & \\
\hline ENE & & & 0.06 \\
\hline Yes & $10(31.2)$ & $10(58.8)$ & \\
\hline No & $22(68.8)$ & $7(41.2)$ & \\
\hline Grade & & & 0.52 \\
\hline । & $14(43.8)$ & $10(58.8)$ & \\
\hline$\|$ & $10(31.3)$ & $3(17.6)$ & \\
\hline III & $8(25)$ & $4(23.5)$ & \\
\hline LVI & & & 0.02 \\
\hline Yes & $7(21.9)$ & $9(52.9)$ & \\
\hline No & $25(78.1)$ & $8(47.1)$ & \\
\hline \multicolumn{4}{|l|}{ Surgery margin } \\
\hline Clear & $25(78.1)$ & $14(82.4)$ & 0.72 \\
\hline Positive & $7(21.9)$ & $3(17.6)$ & \\
\hline \multicolumn{4}{|l|}{ Adjuvant treatment } \\
\hline Radiotherapy & $3(9.4)$ & $3(17.6)$ & 0.44 \\
\hline Chemoradiotherapy & $21(65.6)$ & $12(70.6)$ & \\
\hline No & $8(25)$ & $2(11.8)$ & \\
\hline Recurrence & & & 0.27 \\
\hline Yes & $22(68.8)$ & $9(52.9)$ & \\
\hline No & $10(31.2)$ & $8(47.1)$ & \\
\hline
\end{tabular}

In multivariate analysis, the only significant independent adverse prognostic factor for OS was the presence of PNI ( $p: 0.02)$. In addition, adjuvant treatment ( $p: 0.001)$ and low pathological $\mathrm{N}$ stage $(p:<0.001)$ were significant independent favorable prognostic factors for DFS (Table 4).

\section{Discussion}

Our results showed that PNI was an independent prognostic indicator in surgically resected HNSCC. Also, in our study, survival was worse in patients with PNI than 


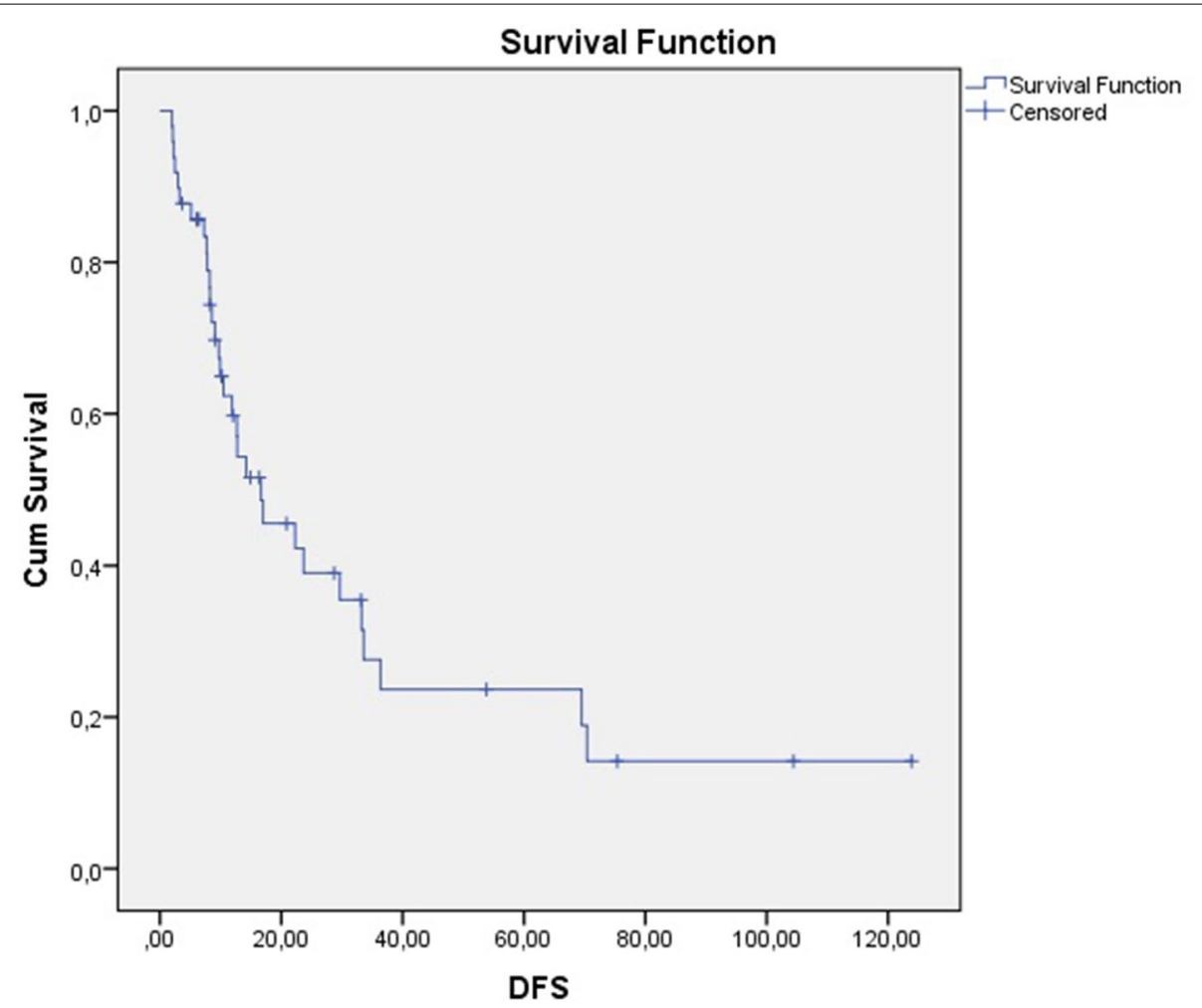

Fig. 1 Kaplan-Meier curve of DFS for all patients

in ENE positive patients, and the presence of ENE did not significantly affect DFS and OS.

PNI is defined as the ability of cancer cells to invade in, around, and through nerves and was first described by Batsakis [7]. Currently, the definition proposed by Liebig is the most widely used and referenced. According to this definition, PNI is considered positive if the presence of tumor cells is detected in any of the three layers of the nerve sheath or if the tumor is close to the nerve and surrounds at least $33 \%$ of the nerve [8]. The incidence of PNI in HNSCC is approximately $40 \%$ [9]. And, PNI was diagnosed in $34.7 \%$ of tumors in our study.

PNI is considered as an adverse feature used in patient selection for postoperative adjuvant therapy in HNC. In a review evaluating whether adjuvant radiotherapy improves locoregional control and survival in HNSCC patients with PNI, in the absence of other indications for adjuvant therapy, 13 relevant retrospective studies were found and analyzed. Among these studies, three studies recommended adjuvant $\mathrm{RT}$, and five studies showed that adjuvant RT was not beneficial [10]. Therefore, there is insufficient evidence to support current guidelines recommending adjuvant RT for all patients with early-stage HNSCC with PNI in the absence of other indications. However, the presence of PNI is one of the predictive indicators of cervical lymph node metastasis in HNC [11-15]. Also, a significant relationship between preoperative otalgia and PNI has been demonstrated in patients with tongue SCC and oral cancer $[16,17]$.

The prognostic importance of PNI is controversial. Although some reports have shown a relationship between PNI and prognosis in HNSCC patients, this is not a general conclusion. However, the prognostic significance of PNI appears to vary depending on the different subtypes and tumor stages of HNSCC. In a retrospective analysis of 194 patients with primary HNC managed surgically with planned adjuvant therapy, PNI was associated with poor OS [18]. PNI was associated with decreased survival in tongue SCC in young adults ( $<40$ years) and buccal cancers, as well as shortening of DFS in cancers of major salivary glands [19-21]. In a study performed in patients with laryngeal SCC treated surgically, the presence of PNI was associated with a significant increased local recurrence rate and shortened DFS, but not regional recurrence and distant metastasis rate [22]. In contrast, in 


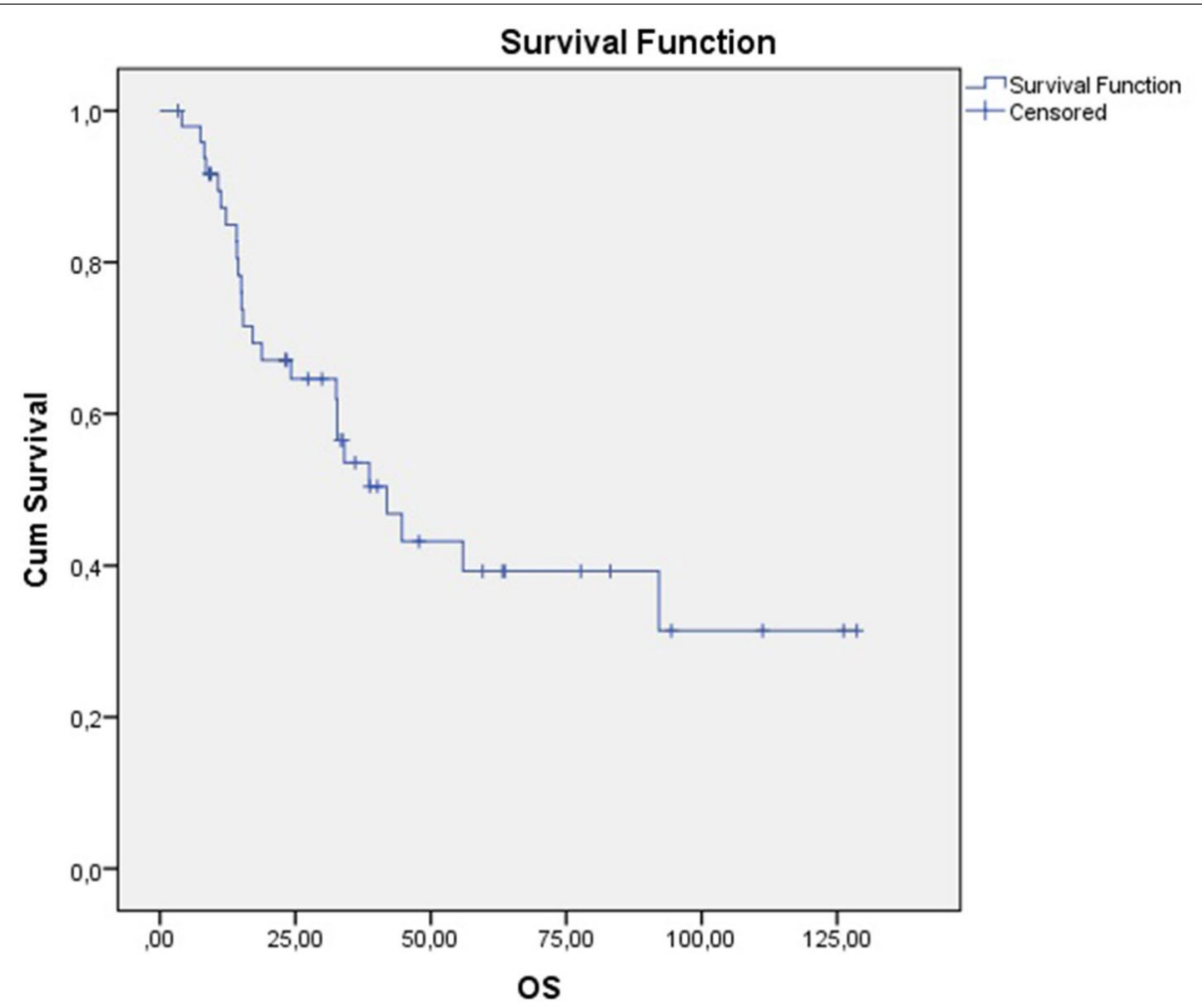

Fig. 2 Kaplan-Meier curve of OS for all patients

oral and oropharyngeal carcinoma, it was significantly associated with regional recurrence and distant metastasis but not with local recurrence [23]. In the study conducted by Fagan JJ et al. in patients who had a primary surgical resection for the oral cavity, oropharynx, hypopharynx, and laryngeal SCC, it has been found that PNI was significantly associated with local recurrence and disease-specific mortality. Also, PNI was associated with an increased risk of local recurrence and cervical metastasis in the only oral cavity and oropharyngeal carcinoma [24]. In a study aimed to determine the risk factors for treatment failure in high-risk head and neck cutaneous squamous cell carcinoma ( $\mathrm{HNcSCC})$ patients treated with surgery, the presence of PNI was significantly associated with worsening DFS than patients without PNI (2-year estimated DFS was $54 \%$ vs. $78 \%$ ) [25]. A meta-analysis of 43 studies of 21,530 patients with HNcSCC demonstrated that poor differentiation, PNI, and Breslow thickness greater than $2 \mathrm{~mm}$ significantly increased the risk of recurrence, metastasis, and disease-specific death [26]. Unlike those presented above, Tourneau $C$ et al. showed in a study in HNC patients treated with surgery and postoperative RT that PNI was not associated with survival [27]. But, in a meta-analysis involving 18 studies and 3894 patients with HNSCC located in different subsites, it has been shown that PNI was statistically associated with poor OS, DFS, and diseasespecific survival (DSS). Additionally, when studies were stratified by tumor location, it has been found that PNI was associated with poor OS in the oral cavity, larynx, and hypopharynx cancers [28]. Besides, Ebrahimi $\mathrm{A}$ et al. found a wide variation depending on immunosuppression, the number and size of nodal metastases, and PNI in DSS. This heterogeneity is thought to be the reason for the AJCC staging system's inability to predict prognosis. It has been reported that more accurate prognosis estimates can be made by integrating these poor prognostic factors into the staging system [29].

\section{Conclusions}

The findings of our study showed an independent association between PNI and poor prognosis in patients with HNSCC. Additionally, in terms of adverse disease course, the presence of PNI poses a significantly higher threat than ENE added to the 8th edition of the AJCC in 2017. 


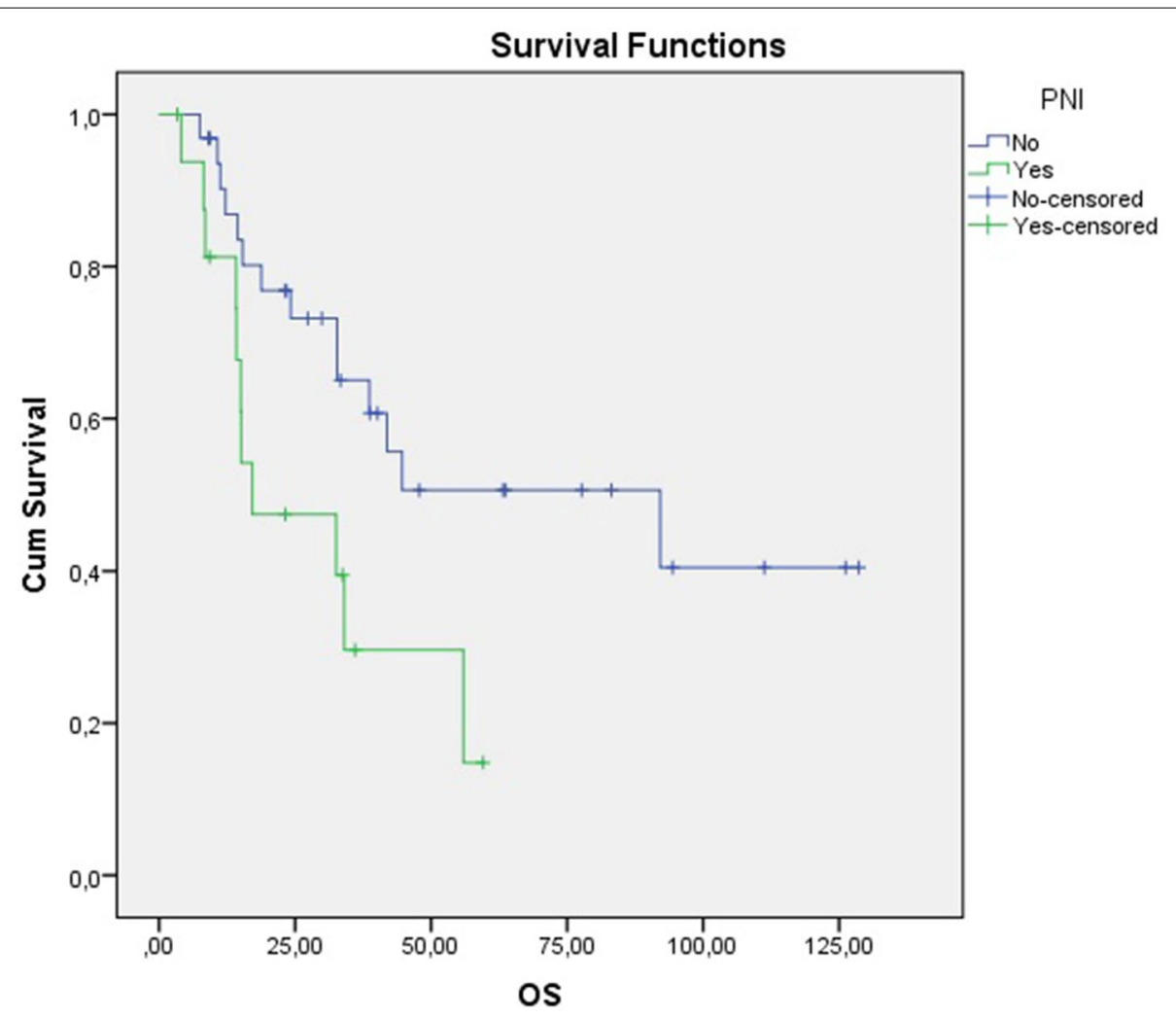

Fig. 3 Kaplan-Meier curve of OS based on PNI

Table 3 Univariate analysis of different variables affecting DFS and OS

\begin{tabular}{lll}
\hline Variables & DFS $\boldsymbol{p}$ value HR (\%95 Cl) & OS $p$ value HR (\%95 Cl) \\
\hline Age (years) & $0.821 .00(0.97-1.03)$ & $0.211 .02(0.98-1.05)$ \\
Sex (men vs. women) & $0.361 .62(0.56-4.66)$ & $0.710 .83(0.31-2.32)$ \\
T stage (T1-2 vs. T3-4) & $0.501 .27(0.62-2.59)$ & $0.820 .91(0.40-2.04)$ \\
N stage (N0-1 vs. N2-3) & $0.0010 .25(0.11-0.57)$ & $0.040 .42(0.18-0.97)$ \\
LVI (yes vs. no) & $0.170 .59(0.28-1.25)$ & $0.340 .67(0.29-1.52)$ \\
PNI (yes vs. no) & $0.500 .76(0.34-1.69)$ & $0.020 .39(0.17-0.88)$ \\
ENE (yes vs. no) & $0.040 .47(0.23-0.97)$ & $0.210 .60(0.27-1.32)$ \\
Adjuvant treatment (yes vs. no) & $0.032 .30(1.04-5.04)$ & $0.831 .11(0.41-2.96)$ \\
\hline
\end{tabular}

LVI lymphovascular invasion, PNI perineural invasion, ENE6 extranodal extension, DFS disease-free survival, OS overall survival

Table 4 Multivariate analysis of different variables affecting DFS and OS

\begin{tabular}{llllll}
\hline Variables & DFS & & & OS \\
\cline { 2 - 3 } \cline { 5 - 6 } & p value & HR (\%95 Cl) & & pvalue & HR (\%95 Cl) \\
\hline N stage (N0-1 vs. N2-3) & $<0.001$ & $0.09(0.02-0.30)$ & 0.05 & $0.42(0.18-0.99)$ \\
PNI (yes vs. no) & - & - & & 0.02 & $0.39(0.17-0.90)$ \\
ENE (yes vs. no) & 0.12 & $2.10(0.81-5.41)$ & & - \\
Adjuvant treatment (yes vs. no) & 0.001 & $4.74(1.92-11.69)$ & & -
\end{tabular}


Therefore, even in the presence of PNI alone without other adverse risk features, adjuvant therapy should be administered.

The main limitations of our study were the retrospective design and the small sample size. Another limitation was that subgroup analysis by tumor location cannot be performed due to the small number of patients.

\begin{abstract}
Abbreviations
AJCC: American Joint Committee on Cancer; DFS: Disease-free survival; DSS: Disease-specific survival; ENE: Extranodal extension; HNC: Head and neck cancers; HNcSCC: Head and neck cutaneous squamous cell carcinoma; HNSCC: Head and neck squamous cell carcinoma; LVI: Lymphovascular invasion; OS : Overall survival; PNI: Perineural invasion; TNM: Tumor, node, metastases; SCC: Squamous cell carcinoma; UICC: Union for International Cancer Control.
\end{abstract}

\section{Acknowledgements}

Not applicable

\section{Authors' contributions}

MKE: written, literature review, controller, and design. MK: written, literature review, and data collecting. MKa: data collecting and English editing. MA: data controller. All authors have read and approved the manuscript.

\section{Funding}

There are no financial interests.

\section{Availability of data and materials}

The datasets used and/or analyzed during the current study are available from the corresponding author on reasonable request.

\section{Declarations}

\section{Ethics approval and consent to participate}

Ethics Committee of Meram Faculty of Medicine, Necmettin Erbakan University, Turkey (Ethics Committee approval number: 2020/2750). The consent to participate is not applicable since it is a retrospective study.

\section{Consent for publication}

Not applicable

\section{Competing interests}

The authors have no conflicts of interest to declare.

Received: 14 June 2021 Accepted: 3 December 2021

Published online: 24 January 2022

\section{References}

1. Marur S, Forastiere AA (2016) Head and neck squamous cell carcinoma: update on epidemiology, diagnosis, and treatment. Mayo Clin Proc 91(3):386-396. https://doi.org/10.1016/j.mayocp.2015.12.017

2. Haque S, Karivedu V, Riaz MK et al (2019) High-risk pathological features at the time of salvage surgery predict poor survival after definitive therapy in patients with head and neck squamous cell carcinoma. Oral Oncol 88:9-15. https://doi.org/10.1016/j.oraloncology.2018.11.010

3. Matsumoto F, Mori T, Matsumura S et al (2017) Prognostic significance of surgical extranodal extension in head and neck squamous cell carcinoma patients. Jpn J Clin Oncol 47(8):699-704. https://doi.org/10. 1093/jjco/hyx055

4. Ajmani GS, Nocon CC, Wang CH, Bhayani MK (2017) Assessment of adjuvant therapy in resected head and neck cancer with high-risk features. Oral Oncol 74:15-20. https://doi.org/10.1016/j.oraloncology. 2017.09.005
5. Bernier J, Domenge C, Ozsahin M et al (2004) Postoperative irradiation with or without concomitant chemotherapy for locally advanced head and neck cancer. N Engl J Med 350(19):1945-1952. https://doi.org/10. 1056/NEJMoa032641

6. Cooper JS, Pajak TF, Forastiere AA et al (2004) Postoperative concurrent radiotherapy and chemotherapy for high-risk squamous-cell carcinoma of the head and neck. N Engl J Med 350(19):1937-1944. https:// doi.org/10.1056/NEJMoa032646

7. Batsakis JG (1985) Nerves and neurotropic carcinomas. Ann Otol Rhinol Laryngol 94(4 Pt 1):426-427

8. Liebig C, Ayala G, Wilks JA, Berger DH, Albo D (2009) Perineural invasion in cancer: a review of the literature. Cancer. 115(15):3379-3391. https:// doi.org/10.1002/cncr.24396 Review

9. Huyett P, Gilbert M, Liu L, Ferris RL, Kim S (2017) A model for perineural invasion in head and neck squamous cell carcinoma. J Vis Exp (119). https://doi.org/10.3791/55043

10. Bur AM, Lin A, Weinstein GS (2016) Adjuvant radiotherapy for early head and neck squamous cell carcinoma with perineural invasion: a systematic review. Head Neck 38(Suppl 1):E2350-E2357. https://doi. org/10.1002/hed.24295

11. Magnano M, Bongioannini G, Lerda W et al (1999) Lymph node metastasis in head and neck squamous cells carcinoma: multivariate analysis of prognostic variables. J Exp Clin Cancer Res 18(1):79-83

12. Martín Villares C, Poch Broto J, Ortega Medina L, Iglesias Moreno MC, González Gimeno MJ (2000) Clinical and histological indicators predictive of cervical metastases in laryngeal cancer. Acta Otorrinolaringol Esp 51(4):330-334 Spanish

13. Sparano A, Weinstein G, Chalian A, Yodul M, Weber R (2004) Multivariate predictors of occult neck metastasis in early oral tongue cancer. Otolaryngol Head Neck Surg 131(4):472-476

14. Chen YW, Yu EH, Wu TH, Lo WL, Li WY, Kao SY (2008) Histopathological factors affecting nodal metastasis in tongue cancer: analysis of 94 patients in Taiwan. Int J Oral Maxillofac Surg 37(10):912-916. https:// doi.org/10.1016/j.ijom.2008.07.014

15. Alkhadar H, Macluskey M, White S, Ellis I (2020) Perineural invasion in oral squamous cell carcinoma: incidence, prognostic impact and molecular insight. J Oral Pathol Med 49(10):994-1003. https://doi.org/ 10.1111/jop.13069 Epub 2020 Jun 25. PMID: 32533593

16. Hechler B, Carlson ER, Heidel RE, Fahmy MD, McCoy JM (2020) Are oral pain and otalgia predictive of perineural invasion in squamous cell carcinoma of the oral tongue? J Oral Maxillofac Surg 78(8):1418-1426. https://doi.org/10.1016/j.joms.2020.03.029

17. Du KN, Shepherd AJ, Ma IV, Roldan CJ, Amit M, Feng LMS et al (2020) Lack of association between angiotensin-converting enzyme inhibitors and angiotensin receptor blockers and pain improvement in patients with oral cancer. Ecancermedicalscience. 14:1121. https://doi.org/10. 3332/ecancer.2020.1121

18. Lee DY, Abraham J, Ross E, Ridge JA, Lango MN, Liu JC et al (2021) Rapid recurrence in head and neck cancer: underappreciated problem with poor outcome. Head Neck 43(1):212-222. https://doi.org/10.1002/hed.26479

19. Marinelli LM, Chatzopoulos K, Marinelli JP, Chen TY, Collins AR, Sotiriou S et al (2020) Clinicopathologic predictors of survival in buccal squamous cell carcinoma. J Oral Pathol Med 49(9):857-864. https://doi.org/ 10.1111/jop.13046

20. Myers JN, Elkins T, Roberts D, Byers RM (2000) Squamous cell carcinoma of the tongue in young adults: increasing incidence and factors that predict treatment outcomes. Otolaryngol Head Neck Surg 122(1):44-51

21. Hocwald E, Korkmaz H, Yoo GH et al (2001) Prognostic factors in major salivary gland cancer. Laryngoscope. 111(8):1434-1439

22. Yilmaz T, Hosal AS, Gedikoğlu G, Onerci M, Gürsel B (1998) Prognostic significance of vascular and perineural invasion in cancer of the larynx. Am J Otolaryngol 19(2):83-88

23. Rahima B, Shingaki S, Nagata M, Saito C (2004) Prognostic significance of perineural invasion in oral and oropharyngeal carcinoma. Oral Surg Oral Med Oral Pathol Oral Radiol Endod 97(4):423-431

24. Fagan JJ, Collins B, Barnes L, D’Amico F, Myers EN, Johnson JT (1998) Perineural invasion in squamous cell carcinoma of the head and neck. Arch Otolaryngol Head Neck Surg 124(6):637-640

25. Trosman SJ, Zhu A, Nicolli EA, Leibowitz JM, Sargi ZB (2021) High-risk cutaneous squamous cell cancer of the head and neck: risk factors 
for recurrence and impact of adjuvant treatment. Laryngoscope. 131(1):E136-E143. https://doi.org/10.1002/lary.28564 Epub 2020 Feb 17. PMID: 32065413

26. Zeng S, Fu L, Zhou P, Ling H (2020) Identifying risk factors for the prognosis of head and neck cutaneous squamous cell carcinoma: a systematic review and meta-analysis. PLoS One 15(9):e0239586. https://doi.org/10.1371/journal.pone.0239586 PMID: 32991600; PMCID: PMC7523977

27. Le Tourneau C, Jung GM, Borel C, Bronner G, Flesch H, Velten M (2008) Prognostic factors of survival in head and neck cancer patients treated with surgery and postoperative radiation therapy. Acta Otolaryngol 128(6):706-712. https://doi.org/10.1080/00016480701675668

28. Zhu J, Zhou R, Wang Y, Yu M (2019) Perineural invasion as a prognostic factor in head and neck squamous cell carcinoma: a systematic review and meta-analysis. Acta Otolaryngol 139(11):1038-1043. https://doi. org/10.1080/00016489.2019.1655167

29. Ebrahimi A, Luk PP, Low H, McDowell L, Magarey MJR, Smith PN et al (2020) The American Joint Committee on Cancer staging for metastatic head and neck cutaneous squamous cell carcinoma: a multi-institutional study of within-stage heterogeneity and impact on prognostic performance. Head Neck 42(11):3235-3242. https://doi.org/10.1002/ hed.26369 Epub 2020 Aug 25. PMID: 32840938

\section{Publisher's Note}

Springer Nature remains neutral with regard to jurisdictional claims in published maps and institutional affiliations.

\section{Submit your manuscript to a SpringerOpen ${ }^{\odot}$ journal and benefit from:}

- Convenient online submission

- Rigorous peer review

- Open access: articles freely available online

- High visibility within the field

- Retaining the copyright to your article

Submit your next manuscript at $\boldsymbol{\nabla}$ springeropen.com 